\title{
Editorial
}

\section{Nono Congresso Europeu de Terapia Ocupacional: Ocupação e Diversidade para o Futuro}

\author{
Sandra Maria Galheigo ${ }^{1}$, Claudia Pellegrini Braga ${ }^{2}$
}

Em maio de 2012 foi realizado em Estocolmo, Suécia, o $9^{\circ}$ Congresso Europeu de Terapia Ocupacional, organizado pelo Conselho de Terapeutas Ocupacionais para os Países Europeus (COTEC) e pela Associação Sueca de Terapeutas Ocupacionais. O tema central do congresso, Occupation Diversity for the Future, teve como motivação a crescente diversidade na Europa em relação às populações, culturas, idiomas, religiões e idades. O congresso também destacava o fato de 2012 ser o Ano Europeu do Envelhecimento Ativo e Saudável.

O programa científico do evento foi composto de cerca de 570 resumos de 45 países, que versavam sobre 23 temáticas distintas em diálogo com a questão da diversidade, sendo o maior número de trabalhos nos temas de: intervenções em terapia ocupacional, avaliação, desenvolvimento profissional e população em situação de vulnerabilidade. Havia um número menor de trabalhos voltados para os temas da moradia, escola, integração local e gênero. Em relação à prática profissional, foi significativo o número de trabalhos com a população idosa e o fato do tema da avaliação aparecer em relação aos diferentes contextos e com distintas populações.

As três conferências principais abordaram a questão da saúde e do bem-estar por meio da diversidade ocupacional, a participação social influenciando o redesenho da pesquisa, da educação e da prática da terapia ocupacional, e o enfrentamento da vida cotidiana pelo paciente e o terapeuta ocupacional.

As oficinas oferecidas durante o congresso atraíram, de forma significativa, o interesse dos participantes. Suas temáticas enfatizavam os desafios para o desenvolvimento curricular, da pesquisa e da prática profissional em seu diálogo com questões relativas à diversidade, cultura e justiça social. Merecem também destaque, em relação às oficinas, a discussão de diretrizes para a terapia ocupacional e seu papel para o desenvolvimento comunitário na Europa, a importância da pesquisa-ação nos estudos sobre ocupação, a inclusão de estudantes com deficiência no ensino superior, e as pesquisas sobre migração e ocupação.

Participaram do evento alguns terapeutas ocupacionais brasileiros, totalizando sete apresentações orais e oito pôsteres nacionais. A experiência possibilitou a divulgação de reflexões e cenários da prática da terapia ocupacional no Brasil, além de criar a oportunidade para contato com profissionais e pesquisadores de diferentes países.

Considerando o conjunto dos trabalhos apresentados no congresso, é possível notar uma tendência para a reflexão de questões e desenvolvimento de práticas focadas na escuta dos desejos, necessidades e demandas da população atendida, enfatizando a importância do diálogo com a diversidade, cultura e participação social dos usuários nos serviços. Em suma, a participação no $9^{\circ}$ Congresso Europeu de Terapia Ocupacional possibilitou a inserção em um fórum internacional de compartilhamento de ideias, apresentações de pesquisas, de práticas e de desenvolvimento de projetos pedagógicos, e de discussões relevantes para a prática da Terapia Ocupacional.

\footnotetext{
1. Professora doutora, docente do Departamento de Fisioterapia, Fonoaudiologia e Terapia Ocupacional da Faculdade de Medicina da Universidade de São Paulo - FMUSP.

2. Terapeuta ocupacional, técnica do Departamento de Fisioterapia, Fonoaudiologia e Terapia Ocupacional da Faculdade de Medicina da Universidade de São Paulo - FMUSP.
}

Endereço para correspondência: Centro de Docência e Pesquisa em Terapia Ocupacional da FMUSP, Rua Cipotânea, 51 - Cidade Universitária, 05508-900, São Paulo - SP.. 